\title{
MENGANTISIPASI DAN MENGATASI KECANDUAN GAMES ONLINE DALAM PERSPEKTIF TEOLOGI INJILI
}

\author{
Martin Elvis \\ Sekolah Tinggi Teologi Cipanas \\ Email: martin.elvis@sttcipanas.ac.id
}

\begin{abstract}
The development of technology is so rapid at present, the products produced greatly affect human life; either the ones that provide benefits or the ones that causes negative impacts. Parents, teachers and clergies finally see the importance of educating the adolescents to prevent and overcome the negative impact of online games addiction. Is the integrative and holistic Christian faith formation able to prevent and overcome the negative impact of the addiction? This paper is a result of a research that claims that the integrative and holistic Christian faith formation is able to lower the level of the addiction at the adolescents, especially at the younger children. While for those who don't have any Christian faith formation, increase their level of addiction. In conclusion, it should be taken a precaution in order to avoid the teenagers from online games addiction by equipping them with training as early as possible. And for those who are in serious level of addiction, it is encouraged to take the integrative and holistic Christian faith formation.
\end{abstract}

Key Words: Christian faith, formation, integrative, holistic, addiction, online games.

\begin{abstract}
ABSTRAK: Perkembangan teknologi begitu pesat saat ini, produk-produk yang dihasilkan sangat memengaruhi kehidupan manusia, baik itu yang bermanfaat, maupun yang dapat menimbulkan dampak negatif. Orang tua, guru dan rohaniwan melihat pentingnya perhatian pada pembinaan anak remaja agar dapat mencegah dan mengatasi pengaruh negatif kecanduan games online ini. Apakah pembinaan iman Kristen yang integratif dan holistik dapat mengantisipasi dan mengatasi pengaruh negatif kecanduan games online terhadap anak remaja? Tulisan ini adalah hasil penelitian yang menyatakan bahwa pembinaan iman Kristen yang integratif dan holistik dapat menurunkan tingkat kecanduan terhadap games online pada anak remaja, khususnya pada anak-anak yang berusia lebih muda. Sedangkan anak-anak remaja yang tidak mendapatkan pembinaan iman Kristen, semakin meningkat tingkat kecanduan terhadap games online. Jadi kesimpulannya, perlu diambil langkah antisipasi agar anak-anak remaja tidak semakin tinggi tingkat kecanduannya terhadap games online dengan mengadakan pembinaan sejak dini. Sedangkan untuk mereka yang telah tinggi tingkat kecanduannya, dapat diambil langkah mengatasinya dengan memberikan pembinaan iman Kristen yang integratif dan holistik.
\end{abstract}

Kata Kunci: Iman Kristen, pembinaan, integratif, holistik, kecanduan, games online.

\section{PENDAHULUAN}

Ada empat perubahan hidup yang memengaruhi perubahan dalam pelayanan konseling; yang pertama adalah kesibukan hidup dalam masyarakat perkotaan; yang kedua adalah perkembangan teknologi yang mengubah gaya hidup dan cara bekerja; yang ketiga adalah membanjirnya informasi; yang keempat adalah dampak dari bioteknologi (Collins, 2007, p. 11). Pelayanan seorang konselor distimulasi oleh perubahan orang yang dikonseling. Jika perkembangan teknologi dengan menghadirkan produkproduk seperti games online yang dapat membuat orang kecanduan, maka pelayanan pastoral dan kon- seling terhadap dampak perkembangan teknologi masa kini juga mengalami perubahan, yaitu perlu mencermati perubahan perkembangan teknologi untuk dapat mengantisipasi dan mengatasi dampak negatif yang telah dan akan ditimbulkan.

Perkembangan di dunia digital begitu pesat pada zaman ini, kemudian, diikuti dengan berbagai macam games online yang sangat mempengaruhi, dan berdampak negatif. Menurut hasil survei Asosiasi Penyelenggara Jasa Internet Indonesia (APJII) sepanjang tahun 2018, dengan menggunakan data lapangan 9 Maret sampai 14 April 2019. Pengguna internet di Indonesia bertumbuh $10.12 \%$ atau 7,9 ju- 
ta menjadi 171.17 juta, atau $64.8 \%$ dari populasi penduduk. Sebagian besar mengakses internet menggunakan smartphone (APJII, 2018, p. 1). Dari data tersebut dapat diambil kesimpulan bahwa betapa pentingnya memperhatikan jumlah pengakses internet yang terus bertambah dan mempengaruhi gaya hidup sebagian besar masyarakat Indonesia, khususnya dalam penelitian ini menfokuskan pada video games yang diakses online melalui internet.

Kehausan akses informasi melalui internet bukan hanya di kota besar, tetapi juga sampai di pedesaan. Ada sebuah kota di Indonesia, di mana akses internet sangat sulit dan mahal. Akses yang paling murah pulsanya adalah pada saat tengah malam sampai dini hari. Dapat dibayangkan berapa banyak anak-anak sekolah dari SD sampai SMA yang haus akan informasi dan hiburan, bermain games online, memanfaatkan akses internet yang berbiaya lebih murah pada waktu tersebut. Bagaimana mungkin mereka bisa belajar dengan baik ketika masuk sekolah di pagi hari tanpa cukup waktu tidur, pasti mereka akan kehilangan konsentrasi karena mengantuk. Jika tidak bijak menggunakan media internet, akan berdampak buruk bukan hanya pada masalah studi, tetapi juga aspek lainnya seperti kesehatan fisik, kesehatan mental, dan kesehatan spiritual. Dari sekian banyak pengaruh negatif penggunaan multimedia dan media sosial melalui media internet, penulis meneliti pengaruh negatif games online, games komputer yang sekarang digandrungi adalah games online, yaitu permaian games lewat jalur internet, yang memungkinkan bermain bersama orang lain yang tidak sama lokasinya. Ini menambah seru permainan, sehingga banyak pemain games online menghabiskan waktu di games center. Permasalahan yang nyata berdasarkan hasil survei dari penulis sendiri memperlihatkan bahwa alokasi waktu untuk bermain games komputer cukup signifikan, bahkan ada yang terlalu lama (lihat tabel 1). Survei dilakukan oleh penulis kepada 665 anak-anak SD kelas empat hingga SMP kelas tiga di salah satu sekolah Kristen di Jabodetabek.
Tabel 1. Waktu untuk Bermain games

Pertanyaan: Rata-rata, berapa lama waktu yang kamu gunakan untuk bermain games setiap hari?

\begin{tabular}{|r|r|r|}
\hline Waktu & Persentase & Jumlah jawaban \\
\hline$<1$ jam & $28,2 \%$ & 185 \\
\hline $1-2$ jam & $27,4 \%$ & 180 \\
\hline $2-3$ jam & $16,0 \%$ & 105 \\
\hline $3-4$ jam & $10,8 \%$ & 71 \\
\hline $4-5$ jam & $5,6 \%$ & 37 \\
\hline $5-6$ jam & $4,9 \%$ & 32 \\
\hline $6-7$ jam & $1,8 \%$ & 12 \\
\hline $7-8$ jam & $1,5 \%$ & 10 \\
\hline$>8$ jam & $3,7 \%$ & 24 \\
\hline \multicolumn{2}{|c|}{ Yang menjawab pertanyaan } & 656 \\
\hline \multicolumn{2}{|c|}{ Yang tidak menjawab } & 9 \\
\hline
\end{tabular}

Hasil survei penulis memperlihatkan bahwa hal ini telah berdampak negatif terhadap hampir separuh anak-anak yang mengikuti survei, terdapat tiga ratus delapan belas anak yang menjawab dan tiga ratus empat puluh tujuh anak yang tidak memberikan respons (lihat tabel 2).

Tabel 2. Perubahan Sikap dan Perilaku Pertanyaan: Apakah ada sikap dan perilaku di bawah ini yang kamu peroleh dari bermain games dan nonton televisi?

\begin{tabular}{|r|r|r|}
\hline Sikap dan Perilaku & Persentase & \multicolumn{2}{|c|}{$\begin{array}{l}\text { Jumlah } \\
\text { jawaban }\end{array}$} \\
\hline Bersikap Kasar & $22,3 \%$ & 71 \\
\hline Berkata Kasar & $36,5 \%$ & 116 \\
\hline $\begin{array}{r}\text { Berkata-kata } \\
\text { "Jorok" }\end{array}$ & $17,0 \%$ & 54 \\
\hline Pemarah & $49,7 \%$ & 158 \\
\hline Pemberontak & $12,9 \%$ & 41 \\
\hline \multicolumn{2}{|r|}{ Yang menjawab pertanyaan } & 318 \\
\hline
\end{tabular}

Dari data objektif hasil wawancara dan survei kepada orang tua maupun anak-anak ditemukan pengaruh negatif yang nyata seperti: kecanduan main games online, perubahan perilaku seperti suka berontak, marah-marah, berkata kasar, melalaikan tugas sekolah, tidak masuk sekolah, berani berbohong, bahkan 
ada anak usia SD yang berani memukul ibunya, ada yang syarafnya terganggu sampai harus masuk rumah sakit, dan ada orang tua yang melaporkan anaknya hilang, tetapi setelah tiga hari kemudian ditemukan di games center. Games online juga mengajarkan filsafat dunia, misalnya konsep dari slogan $g a-$ mes: "Kill or be killed." Konsep ini ditanamkan berulang-ulang ketika anak-anak bermain games yang mengandung unsur kekerasan (Gamepressure, n.d.).

Fondasi dalam proyek penelitian ini adalah Alkitab, kemudian dijabarkan dalam bentuk pembinaan iman Kristen yang integratif dan holistik. Dasar Alkitab diambil dari kitab Ulangan 6:4-9, yang memainkan peranan vital dalam membangun iman yang biblikal (Sanchez, 2003, p. 41). Pengajaran itu harus dilakukan berulang-ulang, proses pengulangan itu akan menghasilkan informasi yang direkam dan disimpan pada memori anak dalam jumlah yang cukup banyak (Darmawan, 2019, p. 26). Bagian firman Tuhan ini adalah perintah TUHAN yang utama, yaitu untuk mengasihi TUHAN dengan segenap hati, dengan segenap jiwa dan dengan segenap kekuatan. Bagian yang sama ditulis dalam Perjanjian Baru, yaitu Matius 22:36-40:

Guru, hukum manakah yang terutama dalam hukum Taurat? Jawab Yesus kepadanya: Kasihilah Tuhan, Allahmu, dengan segenap hatimu dan dengan segenap jiwamu dan dengan segenap akal budimu. Itulah hukum yang terutama dan yang pertama. Dan hukum yang kedua, yang sama dengan itu, ialah: Kasihilah sesamamu manusia seperti dirimu sendiri. Pada kedua hukum inilah tergantung seluruh hukum Taurat dan kitab para nabi.

Jika manusia tidak mengasihi TUHAN, maka ia akan mengasihi dunia, seperti yang tertulis dalam 1 Yohanes 2:15-16

Janganlah kamu mengasihi dunia dan apa yang ada di dalamnya. Jikalau orang mengasihi dunia, maka kasih akan Bapa tidak ada di dalam orang itu. Sebab semua yang ada di dalam dunia, yaitu keinginan daging, dan keinginan mata serta keangkuhan hidup, bukanlah berasal dari Bapa, melainkan dari dunia.

Keduniawian adalah mencintai nilai-nilai dan mengejar kesenangan dunia yang menentang Tuhan atau lebih tepatnya yang meninggikan diri, menyamakan diri sama dengan Tuhan. Keduniawian adalah mencintai dunia yang jatuh dalam dosa. Dunia ini menentang aturan Tuhan dan menggantikannya dengan aturannya sendiri (Mahaney, 2008, p. 23). Orang tua bertanggung jawab untuk membesarkan anak-anak dalam cara yang sehat dengan spiritualitas untuk kebutuhan generasi sekarang (Akdag \& Cingi, 2014, p. 87). Oleh sebab itu betapa pentingnya pengajaran untuk mengasihi TUHAN yang esa. Pendekatan pelayanan untuk anak-anak remaja yang kecanduan games online bukan dimulai dari pendekatan mengatur perilaku dan kebiasaan seperti yang dilakukan oleh beberapa teori yang ada, tetapi dalam penelitian ini dimulai dengan membangun pemahaman iman Kristen yang berpusat pada TUHAN. Amat penting untuk mengenal bukan hanya terhadap ancaman dari kehadiran teknologi, tetapi juga kesempatan untuk taat kepada mandat budaya yang Tuhan berikan. Seorang teolog menegaskan masalah tidak terletak pada teknologi itu sendiri, melainkan pada kerangka moral yang berkurang, yang olehnya dapat berkata kepada manusia bagaimana dengan benar menolak atau menerimanya (Eppinette, 2007, p. 204).

Bagian Alkitab yang diuraikan ini membahas tentang relasi antara Allah dan anak-anak Israel, ini terbukti sebagai model yang sangat berhasil untuk pengembangan teologi keluarga, lebih lanjut dikatakan: "Jika tindakan Allah terhadap Israel diambil sebagai model, maka pelayanan untuk anak oleh orang tua akan memiliki karakteristik: kasih, memerhatikan, merespon, mendisiplin, memberi, menghormati, memahami, dan mengampuni (Balswick \& Balswick, 1991, p. 19-20). Hal ini sangat penting dalam penelitian ini, karena orang tua yang menjadikan tindakan kasih Allah sebagai role model, maka ia juga dapat berperan sebagai role model bagi anakanaknya. Orang tua mengajar tentang Allah kepada anak dalam konteks hidup sehari-hari, yakni segala aktivitas kehidupan yang dijalani menjadi suatu pembelajaran untuk memperkenalkan Allah (Rantesalu, 2018 , p. 159). Semua karakteristik yang dimiliki orang tua akan sangat berpengaruh positif bagi per- 
tumbuhan dan perkembangan karakter dan spiritual anak. Pembinaan dengan dasar biblika berbeda dengan pendekatan behaviour sciences, yang terdiri dari psikologi, sosiologi dan antropologi. Behaviour sciences terfokus pada perilaku manusia, sedangkan tujuan utama dari Alkitab adalah mengubah perilaku manusia seperti yang tertulis dalam 2 Timotius 3:1517 (Larkin Jr., 1988, p. 131). Menghadapi tantangan teknologi yang memengaruhi perilaku manusia, semangat sola scriptura perlu dibangun kembali sehingga orang Kristen memiliki nilai-nilai kehidupan yang berlandaskan nilai-nilai Alkitab, sehingga menghasilkan spiritualitas yang baik (Katarina \& Darmawan, 2019, p. 90) .

Kebenarannya ialah bahwa segala pengetahuan dimulai, sebagaimana dikatakan dalam Kitab Amsal, dengan 'takut akan TUHAN'. Segala pengetahuan diawali dengan terlebih dahulu bertanya, "Apa yang difirmankan Allah? Bagaimana Allah menghendaki kita melihat perkara ini?" (Welch, 2012, p. 7). Dengan memiliki pemahaman iman Kristen, yaitu hidup mengasihi Tuhan serta taat melakukan firman-Nya, anak-anak remaja dengan iman dapat berkata "tidak" terhadap segala godaan, termasuk di dalamnya godaan untuk bermain games online melebihi batas normal, yang menjadikan mereka kecanduan.

Dalam menghadapi anak-anak muda yang sering tidak taat dan tidak disiplin, anak-anak muda memerlukan bentuk disiplin yang korektif (mengatasi) dan preventif (mencegah). Biasanya disiplin hanya dilihat sebagai tindakan korektif. Lebih lanjut dikatakan, tujuan dari disiplin adalah menolong anakanak bertumbuh dalam kedewasaan Kristen dan memberi dorongan untuk mendisiplin diri sendiri. Tetapi fondasi yang menjadi prinsip dalam pendekatan yang efektif untuk mendisiplin adalah "unconditional love" yaitu kasih Allah Bapa untuk anak-anak yang harus diperhatikan orang tua (Les, 2008, p. 10). Pada zaman pascamodern ini, segala sesuatu yang nyata adalah dunia yang tidak nyata (maya). Manusia dapat digambarkan sedang memakai helm yang memisahkannya dari dunia nyata. Manusia dapat mengalami dunia ini dan kehilangan diri di dalamnya. Manu- sia tidak menciptakan realitas hidup, tetapi menerima realitas yang dibuat oleh orang lain (Veith, 1994, p. 61). Dunia yang tidak nyata (maya) inilah yang ada, salah satunya adalah di dalam dunia games onli$n e$. Dengan penerapan firman yang bernilai dari standar Tuhan, diharapkan anak-anak dapat melihat apa yang mereka selama ini abaikan, yaitu melakukan tugas mereka dengan bertanggung jawab, antara lain: tekun belajar, memakai waktu dengan bijaksana, menghormati orang tua, mengasihi Tuhan dan melakukan firman-Nya, serta berperilaku baik dan tidak kecanduan games online, tidak hidup di dunia maya, melainkan melaksanakan tugas dan tanggung jawabnya di dunia nyata. Anak-anak remaja adalah sebuah kategori usia sekitar dua belas hingga lima belas tahun, yang telah masuk SMP. Usia ini dapat juga disebut sebagai usia tunas remaja. Karena pada usia ini mereka telah dapat menerima pemahaman pandangan dunia dari iman Kristen. Pada usia masa remaja awal, individu mulai memperhitungkan sudut pandang orang lain. Hubungan antar pribadi dipahami melibatkan para pemain, berbagai alternatif dan memiliki konsekuensi khusus dari keputusan yang dibuat (Meier, Minirth, Wichern, \& Ratcliff, 2004, p. 43).

Dari uraian di atas, tujuan penelitian ini mau melihat apakah pembinaan iman Kristen yang integratif dan holistik dapat mengantisipasi dan mengatasi anak-anak remaja yang kecanduan terhadap games online.

\section{METODE}

Metode penelitian berdasarkan penelitian literatur, yang kemudian diterapkan melalui survei di lapangan. Dalam penulisan ini penulis membatasi penelitian pada media games, yang untuk selanjutnya penulis sebut sebagai games online. Pembatasan ini dilakukan agar penelitian lebih terfokus, karena sepanjang pelayanan pastoral penulis selama kurang lebih empat belas tahun, ditemukan banyak dampak negatif, khususnya akibat dari kecanduan games online pada anak-anak remaja.

Sumber data pertama adalah dari hasil survei terhadap 665 anak-anak SD kelas empat hingga 
SMP kelas tiga di salah satu sekolah Kristen di Jabodetabek, untuk melihat berapa banyak waktu yang mereka pakai untuk bermain games online, juga untuk melihat perubahan sikap dan prilakunya. Sumber data kedua adalah dari 175 siswa SMP yang mengikuti Pre-Test, diambil 80 siswa dengan nilai kecanduan terhadap games online yang tertinggi. Hasil Post-Test adalah dari 80 siswa yang sama, yang diba-gi dalam 2 kelompok: kelompok 1 terdiri dari 40 siswa yang mendapat pembinaan, dan kelompok 2 terdiri dari 40 siswa yang tidak mendapat pembinaan. Hasil Post-test terhadap kedua kelompok kemudian dibandingkan untuk mengetahui apakah pembinaan terhadap siswa dapat mengantisipasi dan mengatasi tingkat kecanduan games online terhadap siswa.

Penerapan yang dilakukan adalah dengan pembinaan iman Kristen yang integratif dan holistik, berdasarkan Alkitab dan teologi yang bersumber dari Alkitab, khususnya dalam kitab Ulangan 6:4-9. Meskipun demikian, sumbangsih dari teori pengembangan, psikologi dan sains tidak diabaikan. Dalam membahas integrasi psikologi dan teologi, diadakan pendekatan "engagement," "integrasi yang mengizinkan setiap ilmu untuk melakukan apa yang terbaik. Psikologi memperlihatkan sesuatu yang tidak terlihat untuk mengerti perilaku manusia dan aktivitas natural dengan lebih akurat dan lebih lengkap, sedangkan teologi berfungsi untuk melayani, mengawasi dan mengoreksi (Beck \& Demarest, 2005, p. 22). Penulis percaya bahwa seluruh manusia ada di bawah kuasa dosa, manusia memerlukan anugerah penebusan yang khusus dari Tuhan, sehingga manusia dibebaskan dari ikatan dosa, dan memberikan mereka kekuatan untuk hidup seturut dengan kehendak Tuhan dalam segala aspek hidup. Pandangan yang berkaitan dengan anugerah penebusan yang khusus dari Tuhan, yang melepaskan hati manusia dari berhala dan cara pandang hidup yang salah, yang disebabkan oleh tipu daya iblis dan kebutaan dari dosa, sehingga memampukan mereka melalui iman di dalam Yesus Kristus mendapat pengetahuan yang benar tentang Allah dan kebenaran-Nya terhadap ciptaan-Nya dan seluruh aspek realitas hidup
(Naugle, 2002, p. 260). Pandangan dunia Kristen adalah cara pandang Alkitab yang membuat orang Kristen melihat dunia dengan cara pandang baru: bahwa setiap segi hidup manusia punya potensi dan semua aktivitas yang dilakukan adalah peluang untuk melayani Tuhan, menaati Tuhan, menikmati Tuhan, bersaksi tentang Tuhan, dan memuliakan Tuhan (Mahaney, Cabaniss, Kauflin, Harvey, \& Purswell, 2011, p. 168). Inilah yang diajarkan dalam pembinaan iman Kristen yang integratif dan holistik.

\section{HASIL DAN PEMBAHASAN}

\section{Pembinaan Iman Kristen yang Integratif dan Holistik}

Pelayanan untuk anak remaja yang kecanduan games online berdasarkan prinsip firman Tuhan, serta menerima sumbangsih pengetahuan dari psikologi dan sosial sains. Maka dalam pembinaan iman Kristen bagi siswa disampaikan dalam tujuh aspek penting untuk mengantisipasi dan mengatasi kecanduan games online terhadap anak remaja yaitu:

\section{Hubungan dan Tanggung Jawab dalam Keluarga}

Anak-anak harus menghormati orang tua, demikian juga orang tua harus mengasihi anak-anaknya. Ada relasi yang perlu dibangun, dan relasi yang dibangun dengan baik memungkinkan komunikasi orang tua dan anak akan terjalin dengan baik. Orang tua bertanggung jawab untuk mengajarkan berulangulang (bukan memarahi berulang-ulang) agar anakanak mengasihi Tuhan dan hidup seturut perintahNya, sesuai dengan apa yang tertulis dalam kitab Ulangan 6:4-9. Keluarga adalah agen penyaluran kebenaran spiritual (Gangel \& Wilhoit, 2000, p. 26). Jika orang tua tidak mau mengambil tugas yang penting ini, maka multimedia, khususnya games komputer yang akan mengajarkan mereka berulangulang dan menanamkan konsep dunia yang buruk, misalnya seperti contoh sebuah website mempunyai slogan: Selamat datang di 666 games, kami melayani Anda, yang paling keras, brutal, sadis, dan darah dari flashgames internet. Ingatlah selalu, hanya 
kekerasan digital (Dodson, 2012, p. 51-52). Ketika anak bermain games peperangan, saat bertemu musuh, ia harus segera menembak untuk membunuh, atau ia akan terbunuh. Dari sinilah muncul slogan kill or be killed. Konsep ini akan terus tertanam dalam pikiran pemain games karena games dimainkan berulang-ulang. Di pihak lain, ketika anak pergi ke gereja dan mendengarkan firman Tuhan, misalnya dalam Matius 5:44 yang berkata: "Kasihilah musuhmu dan berdoalah bagi mereka yang menganiaya kamu," mereka mengaminkan saat di gereja, tetapi saat mereka bermain games, ketika menemukan musuh di depan dan ingat firman Tuhan untuk mengasihi musuh dan mereka diam saja, maka mereka "terbunuh." Akibatnya akan timbul pertanyaan, bagaimana mungkin saya mengampuni musuh jika saya akan "terbunuh." Maka sampai tahap ini anak-anak akan berpikir bahwa apa yang diajarkan firman Tuhan tidak sesuai dengan kenyataan yang mereka hadapi dalam dunia games. Inilah pengaruh negatif yang sangat berbahaya. Oleh sebab itu peranan orang tua untuk mengajarkan kepada anak-anak dengan berulang-ulang supaya anak mengasihi Tuhan dan hidup dalam kebenaran-Nya adalah hal yang sangat utama. Jangan sampai konsep yang ditanamkan oleh games komputer menguasai hidup anak-anak.

Relasi antara orang tua dan anak sangat penting, melihat dari perspektif ilmu sosial, menekankan peran orang dewasa untuk menjadi penolong dalam hal emosi dan kognitif, dan berusaha membantu anakanak itu, mereka yang terluka secara psikologis oleh satu dan hal lain sehingga perlu dipulihkan. Anakanak akan bertanya: Di mana orang dewasa dalam kehidupan kami yang bisa kami andalkan, yang bisa kami percaya yang nilai-nilainya bisa diyakini? (Dunn, 2012, p. 158). Hasil penelitian di Korea juga menunjukkan hubungan orang tua dan anak yang tidak dekat dapat mempengaruhi tingkat kecanduan anak terhadap games, temuan penelitian ini telah mengidentifikasi bahwa ada hubungan statistik antara kecanduan game internet, kedekatan orang tua, dan sikap terhadap orang tua (Kim \& Kim 2015, p. 370).

\section{Hubungan dan Tanggung Jawab pada Tuhan}

Hubungan dan tanggung jawab pada Tuhan, yang dapat disebut sebagai spiritualitas anak, perlu dibangun sejak kecil, sesuai dengan perintah Tuhan dalam Ulangan 6:4-9, perintah untuk mengajar anak berulang-ulang untuk mengasihi Tuhan dan hidup dalam kebenaran-Nya, termasuk punya tanggung jawab terhadap Tuhan. Hanya manusia, dikatakan bahwa Tuhan menciptakannya sesuai dengan gambarNya. Keunikan manusia adalah ciptaan yang berbeda dari segala ciptaan. Dalam hal ini, manusia secara langsung bertanggung jawab terhadap Tuhan (Hughes, 1989, p. 4). Sesuai dengan Ulangan 6:4-9, anakanak diajarkan untuk mengasihi Tuhan, ini bukanlah dalam bentuk ritual keagamaan belaka, melainkan suatu hubungan yang indah dengan Tuhan secara pribadi. Kekristenan pada dasarnya bukanlah hukum moral atau rutinitas yang suci, seperti anggapan yang salah yang diyakini selama berabad-abad. Sebaliknya, itu adalah hubungan pribadi yang supranatural dengan Juruselamat pribadi yang supranatural (Packer \& Parret, 2011, p. 10). Hubungan yang indah dengan Tuhan dan menjadikan Ia menjadi pusat hidup akan berpengaruh positif bagi seorang anak. Orang yang menjadikan Tuhan sebagai pusat hidupnya, dan hidup dalam kebenaran-Nya mereka akan didominasi oleh kekayaan perasaan positif yang berkaitan dengan kasih, sukacita dan damai sejahtera, sejalan dengan kondisi fondasi iman pengharapan mereka (Willard, 2002, p. 109). Anak-anak yang memiliki iman akan mampu menolak dan berkata "tidak" terhadap segala godaan, termasuk di dalamnya godaan dari pemakaian games online yang berlebihan hingga sampai tingkat kecanduan. Penolakan dilakukan dengan kesadaran akan tanggung jawab kepada Tuhan untuk hidup sesuai dengan kebenaran firmanNya, yaitu dalam hal bertanggungjawab dalam menggunakan waktu yang Tuhan anugerahkan dengan bijaksana, serta tugas-tugas lain yang sering terabaikan, misalnya belajar dan mengembangkan bakat. Akan menjadi sangat penting bagi orang Kristen dalam dunia digital ini untuk mempunyai sikap bijak- 
sana, bertumbuh dalam pengudusan melalui perubahan hidup dalam iman di dalam Kristus.

Orang Kristen mempunyai dasar firman $\mathrm{Tu}$ han yang dapat menjadi penyaring; mempunyai pandangan dunia Kristen yang akan memberikan mereka kriteria, standar dan kemampuan untuk menguji, sehingga mereka dapat memanfaatkan fungsi dalam lautan informasi baru tanpa tersapu olehnya (Veith, 2000, p. 25-26). Membangun hubungan secara pribadi dengan Allah begitu penting, sebab Allah yang membuka ruang bagi manusia. Di Amerika ada program yang dibuat oleh Youth Ministry and Spirituality Project, yaitu: 'membuka ruang' bagi anak-anak muda pascamodern dalam praktik kontemplasi, yaitu praktik untuk menghasilkan kepekaan yang lebih dalam akan kehadiran Allah (Dunn, 2012, p. 185-186). Bersyukur untuk anugerah Tuhan yang membuka komunikasi dengan manusia melalui firman-Nya dan penebusan dalam Kristus. Orang tua dan anak perlu membangun komunikasi dengan Tuhan dalam doa, berdoa akan memberikan orang Kristen kekuatan. Makin peka dan responsif hati terhadap suara Bapa, orang Kristen makin percaya bahwa Ia mendengarkan doa. Lebih lanjut dikatakan, belajar untuk berdisiplin dalam berdoa akan secara radikal mengubah arah hidup yang sehat (Anderson, 1991, p. 115). Membangun spiritualitas anak sangat penting dalam mencegah dan mengatasi kecanduan games online terhadap anak remaja. Psikologi modern Kristen mengakui bahwa penanganan kecanduan yang efektif harus dibangun dari dasar spiritualitas (Harrison, 1992, p. 7). Jadi dapat disimpulkan bahwa spiritualitas anak dalam hubungan dan tanggung jawab dengan Tuhan perlu dibangun, karena ini adalah perintah Tuhan. Namun hubungan ini bukan bersifat legalistik atau menekankan pada ritual keagamaan belaka, melainkan suatu hubungan yang indah dengan Tuhan, Sang Pencipta. Selain aspek negatif dari penggunaan media, ada juga aspek positifnya. Hasil penelitian menunjukkan bahwa dalam konteks iman Kristen, pemakaian alat digital dapat juga berkontribusi kepada formasi iman personal (Lewis, 2018, p. 529). Jadi menggunakan media sebagai alat, bukan diperalat.

\section{Memahami Tugas Utama, Yaitu Belajar}

Orang tua harus berperan untuk membantu anak remaja dalam menyeimbangkan dan mengalokasikan waktu dengan tepat antara tugas utama mereka untuk belajar dengan berolahraga, bermain, dan lain sebagainya, sehingga anak-anak belajar untuk memberikan prioritas bagi yang utama, dan bukan sebaliknya. Artinya, supaya ia dapat mengambil keputusan yang benar (membedakan yang utama dan yang kurang penting) dan bertanggung jawab untuk pilihan atau keputusan yang ia telah ambil. Seandainya anak mengutamakan main games terlebih dahulu sebelum menyelesaikan tugas sekolah dan belajar, maka pada saat ia mau belajar setelah selesai bermain games, ia sudah dalam keadaan lelah, yang akan mengakibatkan anak tidak lagi bisa belajar dengan baik. Anak remaja yang berusia 10-12 tahun perlu belajar untuk menaati Tuhan. Ini adalah waktu yang penting sekali bagi mereka untuk belajar apa yang Alkitab katakan tentang bagaimana mereka harus hidup, apa pilihan yang mereka perlu putuskan, dan apa yang Tuhan harapkan dari mereka. Mereka bertumbuh kepada kemandirian yang lebih besar dalam kehidupan rohani mereka (Trent, Osborne, \& Bruner, 2000, p. 129). Firman Tuhan berkata: "Karena itu perhatikanlah dengan saksama, bagaimana kamu hidup, janganlah seperti orang bebal, tetapi seperti orang arif, dan pergunakanlah waktu yang ada, karena hari-hari ini adalah jahat" (Ef. 5:16-17). Ayat ini mengingatkan orang Kristen untuk memerhatikan dengan saksama, artinya ini suatu hal yang penting, yaitu bagaimana hidup dan mengalokasikan waktu dengan bijaksana. Hasil penelitian menunjukkan orang tua dan tenaga pendidik harus bekerja sama, untuk mengidentifikasi kebiasaan yang baik dan menemukan cara-cara untuk meningkatkan belajar peserta didik (Julius \& Evans, 2015, p. 140).

\section{Mengembangkan Bakat}

Mengembangkan bakat anak adalah membantu anak untuk mengembangkan kompetensinya. Orang tua perlu untuk menemukan dan memaksimalkan potensi atau bakat anak. Orang tua yang pa- 
ling mengenal anak, yang paling memerhatikan, dan yang dapat melihat bakat dan kecerdasan yang terabaikan oleh sekolah (Fuller, 1994, p. 180). Dalam membesarkan anak, orang tua Kristen harus lebih memilih apa yang Allah inginkan dan kerjakan dalam diri mereka dan tidak memaksakan anak-anak untuk mengikuti apa yang orang tua kehendaki (Pazmino, 2012, p. 317). Sekolah mempunyai peranan penting dalam meningkatkan bakat anak didik, perlu memiliki lebih banyak sumber daya untuk dapat mengelola bakat anak didik, sehingga mereka dapat mengetahui potensi dan bakat unik mereka dan kemudian mengembangkannya. Tenaga pendidik sangat penting dalam mengembangkan bakat anak didik, mereka akan menemukan kekuatan dan kelemahan anak didik karena banyak waktu bersama mereka. Memberi prioritas pengembangan pada segi kekuatan talenta anak didik adalah tugas utama para pendidik (Veladat \& Navehebrahim, 2011, p. 1055).

Jadi, mengembangkan kompetensi anak sangat penting, karena talenta itu adalah karunia dan harus orang Kristen pertanggungjawabkan kepada Tuhan. Pengembangan ini juga berkaitan dengan aspek fisik, mental emosional dan spiritual. Anak-anak perlu ditemukan dan dimaksimalkan potensi bakatnya, bukan keinginan orang tua yang dipaksakan pada anak.

\section{Mempunyai Kehidupan Sosial, Pertemanan yang Baik}

Anak-anak yang asyik bermain games online menjadi kurang bersosialisasi dalam kehidupan nyata dengan teman-teman seusianya. Ditambah dengan sarana dan prasarana untuk bermain bersamasama teman dalam konteks perkotaan yang semakin lama semakin langka, anak-anak lebih memilih bermain melalui jejaring sosial. Bahaya dari teknologi baru membayangi manfaatnya. Meningkatkan kebebasan yang dapat menyebabkan kebejatan moral yang diizinkan; menciptakan komunitas palsu yang secara aktual mengisolasi diri dan bukan bersifat komunal (Veith, 2000, p. 126). Oleh sebab itu anakanak perlu didorong untuk memiliki kehidupan sosial dan pertemanan yang nyata dengan teman-teman seusia apakah itu dalam bentuk bermain bersama, mengerjakan tugas kelompok, belajar bersama, dan lain sebagainya. Relasi harus memperkaya keduanya daripada memperburuk satu atau keduanya, keunikan manusia adalah nilai yang seharusnya tidak menghancurkan relasi sosial. Solidaritas keluarga Yahudi pada zaman Alkitab sangat kuat karena setiap individu saling menguatkan, bukan saling melemahkan (Lewis \& Damarest, 1994, p. 159).

Adalah penting mengajarkan anak tentang arti nilai dari sebuah persahabatan, bagaimana memilih sahabat dengan bijaksana, dan bagaimana menjadi sahabat yang baik bagi orang lain (Kostenberger, 2010, p. 164). Firman Tuhan berkata: "Janganlah kamu sesat: Pergaulan yang buruk merusakkan kebiasaan yang baik" (1 Kor. 15:33). Banyak anak yang terpengaruh dengan teman-teman sepergaulannya. Penelitian menyatakan bahwa pengaruh teman adalah faktor penting yang menyebarkan kecanduan internet dan games (Gunuc, 2016 p. 7). Ketika ada komunitas yang mempunyai kebiasaan buruk, misalnya mulai mengenal merokok, minuman keras, narkotika, pornografi, main games yang mempunyai konten seks, kekerasan, dan lain sebagainya, anak dengan mudah bisa ikut terpengaruh jika ia tidak dapat memilih sahabat dengan bijaksana. Ada tanggung jawab sosial terhadap kecanduan video games (Van Rooij, Meerkerk, Schoenmakers, Griffiths, \& Van De Mheen, 2010, p. 492). Hukum yang terutama dalam Ulangan 6:4-9 dikutip oleh Tuhan Yesus ketika Ia ditanya hukum manakah yang terutama dalam hukum Taurat? Jawab-Nya:

Kasihilah Tuhan, Allahmu, dengan segenap hatiku dan dengan segenap jiwamu, dan dengan segenap akal budimu. Itulah hukum yang terutama dan yang pertama. Dan hukum yang kedua, yang sama dengan itu, ialah: Kasihilah sesamamu manusia seperti dirimu sendiri. Pada kedua hukum inilah tergantung seluruh hukum Taurat dan kitab para nabi (Mat. 22:37-40).

Jadi, mengasihi Tuhan dan sesama adalah perintah yang penting. Di dalam mengasihi sesama juga ditulis seperti mengasihi diri sendiri, juga adalah hal 
yang penting. Hasil penelitian memperlihatkan bahwa manusia cenderung bertindak sesuai dengan keharmonisan mental potret dirinya, orang yang tidak mengasihi diri sendiri secara sehat, tidak akan mungkin mengembangkan hubungan kasih yang sehat dengan orang lain (McDowell, 1984, p. 18). Hasil penelitian menunjukkan adanya keuntungan dan resiko menggunakan media sosial, keuntungannya anakanak memiliki kemampuan komunikasi lebih baik dengan teman-teman, tetapi resikonya dapat menimbulkan depresi, cyberbullying, dan pelecehan seksual online yang harus diwaspadai (Tartari, 2015, p. 328).

\section{Ada Waktu untuk Berolahraga}

Kualitas makanan bergizi dan adanya waktu untuk berolahraga, memegang peranan penting dalam mengembangkan kebiasaan hidup sehat dan gaya hidup. Ini merupakan faktor penting dalam hubungan antara pendidikan dan kesehatan (OECD, 2010, p. 138). Oleh sebab itu diusulkan bagi pihak sekolah untuk mengadakan ekstrakurikuler olahraga di sekolah. Banyak permainan olahraga seperti sepak bola, softball, basket dan lain sebagainya sekarang sudah ada dalam bentuk permainan digital, yaitu dimainkan di komputer atau smartphone. Akibatnya adalah berkurangnya kegiatan olahraga fisik bagi anak-anak, sehingga dapat mengganggu kesehatan, misalnya obesitas, atau sebaliknya, tambah kurus karena kurang istirahat dan makan tidak teratur. Hasil penelitian mengatakan ada bukti yang tak terbantahkan bahwa aktifitas fisik yang teratur berkontribusi pada pencegahan primer dan sekunder dari beberapa penyakit kronis dan dikaitkan dengan penurunan resiko kematian sebelum dewasa. Ada hubungan linier antara aktivitas fisik dan status kesehatan (Warburton, 2006, p. 807).

\section{Ada Waktu untuk Istirahat}

Waktu belajar di sekolah yang cukup panjang serta adanya tugas-tugas sekolah yang harus dikerjakan membuat waktu untuk beristirahat di rumah semakin berkurang jika waktu yang ada tersita untuk bermain games online. Batasan waktu untuk bermain games perlu diterapkan agar anak-anak mempunyai waktu untuk belajar dan mengerjakan tugas sekolah serta beristirahat. Dua jam adalah angka maksimum yang tepat bagi anak untuk hiburan "layar kaca." Angka dua jam ini sejalan dengan pendapat pakar kesehatan dan pakar anak yang terkemuka. America Academic of Pediatrics, misalnya merekomendasikan bahwa anak sebaiknya tidak menonton lebih dari dua jam sehari (Orange \& O'Flynn, 2007, p. 135). Gaya hidup yang hanya duduk saja, tanpa olah raga yang membuat mereka bisa relaksasi juga mempengaruhi prestasi anak remaja. Hasil penelitian terhadap anak remaja, saat mereka diberi pelatihan relaksasi, tarikan nafas panjang dan mengendorkan otot-otot secara berkala, dapat meningkatkan kappasitas memori dan prestasi akademiknya (Flor, Monir, Bita, \& Shahnaz, 2013, p. 612).

\section{Hasil Pre-Test dan Post-Test}

Dari 175 siswa yang mengikuti Pre-Test, diambil 80 siswa dengan nilai kecanduan terhadap $g a$ mes komputer yang tertinggi. Hasil Post-Test adalah dari 80 siswa yang sama, yang dibagi dalam 2 kelompok: kelompok 1 terdiri dari 40 siswa yang mendapat pembinaan, dan kelompok 2 terdiri dari 40 siswa yang tidak mendapat pembinaan. Hasil penelitian: siswa yang mendapat pembinaan iman Kristen untuk kelas 7 dan 8 mengalami penurunan tingkat kecanduan terhadap games komputer, sedangkan untuk siswa kelas 9 tidak signifikan mengalami penurunan tingkat kecanduan terhadap games komputer. Sedangkan siswa kelas 7, 8 dan 9 yang tidak mendapatkan pembinaan iman Kristen mengalami kenaikan tingkat kecanduan terhadap games komputer. Dengan demikian, hasil penerapan di lapangan menunjukkan bahwa pembinaan yang integratif dan holistik berpengaruh kepada para siswa.

Sesuai dengan pembinaan yang melibatkan orang tua di dalam mengantisipasi dan mengatasi kecanduan anak terhadap games online, penelitian Hasan ÖZGÜR juga memberikan usulan, Salah satu tugas terpenting orang tua di era informasi dan komunikasi adalah melindungi anak-anak mereka dari 
efek negatif internet serta membimbing anak-anak mereka ke sumber daya internet yang berguna. Dalam konteks ini, penting bagi orang tua untuk berkomunikasi dengan baik dengan anak-anak mereka dan untuk memberi informasi dan membimbing mereka tentang risiko lingkungan online. Untuk tujuan ini, ada kebutuhan untuk membuat publikasi untuk meningkatkan kesadaran keluarga tentang proses penggunaan internet dan teknologi yang menyertai oleh anak-anak mereka melalui media tertulis dan visual dan sumber daya internet (ÖZGÜR, 2019. p. 60). Hasil Penelitian Vondráčková dan Gabrhelik menyimpulkan, mengembangkan intervensi pencegahan terutama harus menargetkan anak-anak dan remaja yang berisiko kecanduan internet tetapi juga orang tua, guru, teman sebaya, dan lainnya yang merupakan bagian dari lingkungan formatif anak-anak dan remaja yang berisiko kecanduan internet (Vondráčková \& Gabrhelík, 2016, p. 576). Jadi selain anak, orang tua dan teman sebaya juga perlu diperhatikan. Hasil penelitian ini juga diperkuat oleh hasil penelitian yang dilakukan oleh Apisitwasana, Perngpam dan Cottler yang menyimpulkan, program pembelajaran partisipatif dan intervensi berbasis keluarga efektif dalam mengembangkan pengaturan diri terhadap kecanduan games dalam hal meningkatkan pe-

\section{DAFTAR RUJUKAN}

Akdag, M., \& Cingi, M. (2014). The Impact of Internet and Social Media on Kids' and Parents' Game Habits. Epiphany, 7(1). https://doi.org/10.21533/epiphany.v7i1.86

Anderson, L. (1991). Taking Trauma Out of Teen Transitions. Colorado Springs: Navpress.

Apisitwasana, N., Perngparn, U., \& Cottler, L. (2018). Effectiveness of school- and familybased interventions to prevent gaming addiction among grades 4\&ndash;5 students in Bangkok, Thailand. Psychology Research and Behavior Management, Volume 11, 103115. https://doi.org/10.2147/PRBM.S145868

APJII. (2018). Data Pengguna Internet di Indonesia Sepanjang Tahun 2018. Retrieved May 19, ngetahuan dan sikap tentang permainan dan efeknya serta pengaturan diri pada kecanduan games (Apisitwasana, Perngparn, \& Cottler, 2018, p. 114). Dengan demikian antisipasi dan mengatasi kecanduan games online bukan hanya berfokus pada anak, tetapi juga kepada orang tua yang berperanan penting.

\section{KESIMPULAN}

Hasil Analisis literatur menunjukkan bahwa pembinaan iman Kristen yang integratif dan holistik dapat mengantisipasi dan mengatasi pengaruh negatif kecanduan anak remaja terhadap games online. Hasil penelitian dalam penerapan menunjukkan adanya penurunan tingkat kecanduan terhadap games online, terutama pada anak berumur 11 dan 12 tahun (siswa kelas 7 dan 8), sedangkan untuk anak berumur 13 tahun (siswa kelas 9) ada sedikit penurunan tingkat kecanduan tetapi tidak signifikan perubahannya. Untuk kelompok siswa yang tidak menerima pembinaan, hasil tes menunjukkan bahwa tingkat kecanduan terhadap games online semakin meningkat. Jadi dapat disimpulkan, pembinaan iman Kristen yang integratif dan holistik dapat mengantisipasi dan mengatasi pengaruh negatif kecanduan games online terhadap anak remaja.

2019, from https://inet.detik.com/ telecommunication/d-4551132/ini-jumlahpengguna-internet-indonesia-sepanjang2018?_ga=2.33646441.954609948.1558010 383-1461079310.1558010383

Balswick, J. O., \& Balswick, J. K. (1991). The Family: A Christian Perspective on the Contemporary Home. Grand Rapids: Baker.

Beck, J. R., \& Demarest, B. A. (2005). The Human Person in Theology and Psychology: A Biblical Anthropology for the Twenty-First Century. Grand Rapids: Kregel.

Chistie Les. (2008). When Church Kids Go Bad: How to Love and Work with Rude, Obnoxious, and Apathetic Students. Grand 
Rapids: Zondervan.

Collins, G. R. (2007). Christian Counseling: A Comprehensive Guide (Third Edit). Nashville: Thomas Nelson.

Dallas Willard. (2002). Renovation of the Heart. Leicester: IVP.

Darmawan, I. P. A. (2019). Pembelajaran Memorisasi Dalam Ulangan 6:6-9. EPIGRAPHE: Jurnal Teologi Dan Pelayanan Kristiani, 3(1), 21. https://doi.org/10.33991/epigraphe. v3i1.50

David K. Naugle. (2002). Worldview: The History of a Concept. Grand Rapids: Eerdmans.

Dunn, R. R. (2012). Membentuk Kerohanian Anak Muda di Zaman Postmodern. Surabaya: Perkantas.

Eppinette, M. (2007). "Human 2.0; Transhumanism as a Cultural Trend" dalam Everyday Theology (K. J. Vanhoozer, C. A. Anderson, \& M. J. Sleasman, Eds.). Grand Rapids: Baker.

Flor, R. K., Monir, K. C., Bita, A., \& Shahnaz, N. (2013). Effect of Relaxation Training on Working Memory Capacity and Academic Achievement in Adolescents. Procedia - Social and Behavioral Sciences, 82, 608-613. https://doi.org/10.1016/j.sbspro.2013.06.318

Fuller, C. (1994). Maksimalkan Potensi Anak Anda. Bandung: Kalam Hidup.

Gamepressure. (n.d.). Kill or Be Killed. Retrieved May 20, 2020, from https://guides.gamepressure.com/farcry4/guide.asp?ID=28196

Gangel, K. O., \& Wilhoit, J. (2000). The Christian educator's handbook on family life education. Retrieved from http://firstsearch. oclc.org/WebZ/DECRead?standardNoType= $1 \&$ standardNo $=0801022479 \&$ sessionid $=0 \&$ srcdbname $=$ worldcat $\&$ key $=6 \mathrm{c} 994 \mathrm{ac} 16 \mathrm{c} 3 \mathrm{~d} 78$ 05118848a90d49dc64c4a66c694c6137f62a0 ace64aa9f4467\&ectype $=$ MOREINFO http://firstsearch.oclc.org/ WebZ/DCARead?standardNoType $=1 \& \mathrm{~s}$

Gunuc, S. (2016). Peer Influence in Internet and Digital Game Addicted Adolescents: Is
Internet/Digital Game Addiction Contagious? International Journal of High Risk Behaviors and Addiction, Inpress (Inpress). https://doi.org/10.5812/ijhrba.33681

Harrison, R. K. (1992). Encyclopedia of Biblical and Christian Ethics. Revised Edition. Cambridge: Thomas Nelson.

Hughes, P. E. (1989). The true image: the origin and destiny of man in Christ. Grand Rapids, Mich.: Eerdmans.

Jonathan K. Dodson. (2012). Gospel-Centered Discipleship. Wheaton, IL: Crossway.

Julius, M., \& Evans, A. S. (2015). Study of the relationship between study habits and academic achievement of students: A case of Spicer Higher Secondary School, India. International Journal of Educational Administration and Policy Studies. https://doi.org/10.5897/ijeaps2015.0404

Katarina, K., \& Darmawan, I. P. A. (2019). Alkitab dalam Formasi Rohani pada Era Reformasi Gereja dan Implikasi bagi Gereja Pada Masa Kini. EPIGRAPHE: Jurnal Teologi Dan Pelayanan Kristiani, 3(2), 81. https://doi.org/10.33991/epigraphe.v3i2.85

Kim, K., \& Kim, K. (2015). Internet Game Addiction, Parental Attachment, and Parenting of Adolescents in South Korea. Journal of Child \& Adolescent Substance Abuse, 24(6), 366-371. https://doi.org/ 10.1080/1067828X.2013.872063

Kostenberger, A. J. (2010). God, Marriage, and Family: Building the Biblical Foundation. 2nd Edition. Wheaton, IL: Crossway.

Lewis, B. (2018). Social Media, Peer Surveillance, Spiritual Formation, and Mission: Practising Christian Faith in a Surveilled Public Space. Surveillance \& Society, 16(4), 517-532. https://doi.org/10.24908/ss.v16i4.7650

Lewis, G. R., \& Damarest, B. A. (1994). Integrative Theology. Vol.3. Grand Rapids, Mich.: Zondervan.

Mahaney, C. J. (2008). Worldliness. Terjemahan 
oleh Denny Pranolo. Bandung: Pioner Jaya. Mahaney, C. J., Cabaniss, C., Kauflin, B., Harvey, D., \& Purswell, J. (2011). Worldliness: Melawan Godaan Dunia yang Sudah Jatuh Dalam Dosa. Penerbit Pionir Jaya.

McDowell, J. (1984). His Image My Image. San Bernardino: Here's Life.

Meier, P., Minirth, F., Wichern, F., \& Ratcliff, D. (2004). Pengantar Psikologi dan Konseling Kristen. ANDI.

OECD. (2010). Improving Health and Social Cohesion through Education. https://doi.org/ 10.1787/9789264086319-en

Orange, T., \& O'Flynn, L. (2007). The Media Diet for Kids (E. W. Soekarso, Ed.). Jakarta: Serambi.

ÖZGÜR, H. (2019). Online Game Addiction Among Turkish Adolescents: The Effect of Internet Parenting Style. Malaysian Online Journal of Educational Technology, 7(1), 46-67. https://doi.org/10.17220/mojet.2019.01.004

Packer, J. I., \& Parret, G. A. (2011). Grounded in the Gospel (Membangun Orang Percaya dengan Gaya Lama). Terjemahan Ina Elia Gani. Malang: SAAT.

Pazmino, R. W. (2012). Fondasi Pendidikan Kristen: Sebuah Pengantar dalam Perspektif Injili. Bandung: STTB.

Rantesalu, S. B. (2018). Kompetensi Pedagogik Menurut Analisis Ulangan 6:7-9 dengan Pendekatan Hermeneutik Schleiermacher. BIA': Jurnal Teologi Dan Pendidikan Kristen Kontekstual, 1(2), 153-163. https://doi.org/10.34307/b.v1i2.14

Sanchez, E. (2003). Family in The Bible: Exploring Customs, Culture, and Context (R. S. Hess \& M. D. C. R., Eds.). Grand Rapids: Baker.

T. Welch, E. (2012). Apakah Otak yang Dipersalahkan? (I. Tjulianto, Ed.). Momentum.
Tartari, E. (2015). Benefits and Risks of Children and Adolescents Using Social Media. European Scientific Journal, 11(13), 321332. Retrieved from http://citeseerx.ist. psu.edu/viewdoc/download?doi=10.1.1.917. $4541 \&$ rep $=$ rep $1 \&$ type $=$ pdf

Trent, J., Osborne, R., \& Bruner, K. (2000). Parent's Guide to the Spiritual Growth of Children. Tyndale House Publishers.

Van Rooij, A. J., Meerkerk, G.-J., Schoenmakers, T. M., Griffiths, M., \& van de Mheen, D. (2010). Video game addiction and social responsibility. Addiction Research \& Theory, 18(5), 489-493. https://doi.org/ $10.3109 / 16066350903168579$

Veith, G. E. (1994). Postmodern times: a Christian guide to contemporary thought and culture. Retrieved from http://books.google.ro/ books?id=GRRoUx8yHxEC

Veith, G. E. (2000). Christian in a .com World. Wheaton, IL: Crossway.

Veladat, F., \& Navehebrahim, A. (2011). Designing a model for managing talents of students in elementary school: A qualitative study based on grounded theory. Procedia - Social and Behavioral Sciences. https://doi.org/ 10.1016/j.sbspro.2011.11.338

Vondráčková, P., \& Gabrhelík, R. (2016). Prevention of Internet addiction: A systematic review. Journal of Behavioral Addictions, 5(4), 568-579. https://doi.org/10.1556/ 2006.5.2016.085

Warburton, D. E. R. (2006). Health benefits of physical activity: the evidence. Canadian Medical Association Journal, 174(6), 801809. https://doi.org/10.1503/cmaj.051351

William J. Larkin Jr. (1988). Cultural and Biblical Hermeneutics: Interpreting and Applying the Authoritative Word in a Relativistic Age. Grand Rapids: Baker. 